\title{
Photosystem II Photochemistry and Chlorophyll Intensity in Rice (Oryza sativa L.) under Drought at Flowering Stage
}

\section{Selukash Parida ${ }^{2}$, Goutam Kumar Dash ${ }^{1}$, Madhusmita Barik ${ }^{1}$, Soumya Kumar Sahoo ${ }^{1}$, Rajendra Kumar Panda ${ }^{2}$, Mirza Jaynul Baig ${ }^{1}$, Padmini Swain ${ }^{1 *}$}

${ }^{1}$ Crop Physiology and Biochemistry Division, ICAR-National Rice Research Institute, Cuttack, Odisha, India

${ }^{2}$ Department of Plant Physiology, Odisha University of Agriculture and Technology, Bhubaneswar, Odisha, India

*Corresponding author

A B S T R A C T

\section{Keywords}

PSII

Photochemistry,

Chlorophyll

fluorescence,

Fv/Fm, ETR

\section{Article Info}

Accepted:

07 January 2021

Available Online:

10 February 2021
Drought is the major environmental stress that affects the photosynthetic process of the plants. Chlorophyll fluorescence analysis is one of the robust techniques to understand the activity of PS II photochemistry in rice under drought. Fourteen rice genotypes including two contrasting controls (Sahabhagidhan and IR 64 as tolerant and susceptible controls respectively) were used to evaluate the PSII activity. The drought was imposed at the flowering stage by maintaining stressed pots at $50 \%$ field capacity. Results showed that drought tolerant genotypes i.e. Parijata, IC 516130, IC 516008 and IC 516149 possessed higher value for chlorophyll fluorescence parameters such as maximum Fluorescence (Fm), maximum quantum yield of PSII photochemistry (Fv/Fm), maximum primary yield of PSII photochemistry (Fv/F0), and these values were strongly correlated with total chlorophyll content, RWC, and LWP. Overall, this experiment signifies the suitability of chlorophyll fluorescence parameters for phenotyping of genotypes for drought tolerance.

\section{Introduction}

Rice is the principal and dominant food crop contributing nearly $45 \%$ of the total food grain production and provides livelihood to two third of rural population (Eliazer Nelson et al., 2019). By 2030, there is a need of 120 million tonnes of rice grains to feed the growing population in India (CRRI-ICAR, 2011). Out of 159.7 million hectares of cultivable land about one fifth of rice cultivation area is prone to drought stress (Geda et al., 2019). In rainfed low lands, medium low lands and uplands, drought stress is the most vital factor that lower grain yield by affecting the photosynthetic machinery (Vikram et al., 2011).

In further, the scenario may become worst if the frequency and intensity of drought will increase. However, yield loss due to drought may be avoided by developing tolerant 
genotypes that are more resilient to drought stress. In fact, identification and characterization of genotypes with different mechanism of drought tolerance would be a promising approach (Swain et al., 2017). To screen large population, robust and less time consuming techniques are required. Measurement of photosynthetic efficiency is an efficient method to screen large population. Minimal damage of photosynthetic performance is one of the basic requirements for effective rice production. Better consistency of photosynthetic apparatus poses a real key for tolerant genotypes. Photosynthetic apparatus mainly photosystem II (PS II) is damaged severely under different stresses (Sone et al., 2012; Sarkar and Ray, 2016).

Chlorophyll fluorescence is a non-destructive, informative and widely used powerful technique to evaluate the health status of photosynthetic apparatus mainly PS II under stress. The study of Fm, Fv, Fv/Fm and Fv/F0 is a key parameter that provides information related to photosynthetic performance or PS II activity. Reduction of these values is an indicator of photoinhibition (Guidi et al., 2019). In the present experiment, an effort has been made to study the performance of PS II activity based on chlorophyll fluorescence techniques under drought stress in rice varieties. Apart from the chlorophyll fluorescence study, relative water content (RWC), leaf water potential (LWP) and chlorophyll content are good indicators for assessing the tolerance level of genotypes under drought (Datta et al., 2012). Higher value of RWC and LWP is the adaptive mechanism for dehydration avoidance and turgor maintenance (Selvaraj et al., 2017). Therefore, the present experiment aimed towards evaluating genotypes for drought tolerance based on chlorophyll fluorescence and development of suitable phenotyping marker that could help in identification of tolerant genotypes.

\section{Materials and Methods}

\section{Experimental site and plant growth}

The experiment was conducted during dry season (DS) -2019 at crop physiology and biochemistry division, National Rice Research Institute-ICAR, Cuttack, Odisha, India. Geographically farm is situated at $85^{\circ} 93^{\prime} \mathrm{E}$ longitude and $20^{\circ} 45^{\prime} \mathrm{N}$ latitude with 23.5 above mean sea level. Fourteen rice (Oryza sativa L.) genotypes (Parijata, IC 516313, IC 516130, ARC 10376, IC 516008, Pathara, Lalat, IR 36, IC 516149, Satabdi, Naveen, Prasad) including two controls (Sahabhagidhan and IR 64 as tolerant and susceptible controls respectively) were selected from the100 genotypes, screened for vegetative stage drought under field condition. The selected genotypes were grown in pots with two treatments (WW-well watered and DS-drought stress) and four biological replications for each treatments in completely randomized design. Each pot was filled with $4 \mathrm{~kg}$ of farm soil. In each pot, 160 $\mathrm{mg}$ of murate of potash and $384 \mathrm{mg}$ of single super phosphate was used before seed sowing. After 15 days of germination, thinning was done to maintain single plant per pot. After thinning, nitrogen in the source of urea was applied at $200 \mathrm{mg}$ per pot. Drought stress was imposed at flowering stage by maintaining the field capacity of the half number of pots at $60 \%$ for 15 days.

\section{Chlorophyll a fluorescence parameters}

Fully expanded second leaf from top of the plants was collected and incubated in dark for 30 minutes. The images were taken using Imaging PAM-MAXI version, Heinz Walz, Effeltrich, Germany and the different fluorescence parameters were analyzed using Imaging win software provided with the instrument.. Data were recorded with the following earlier settings: light intensity $=2$; saturation pulse $=10\left(2700 \mu \mathrm{mol} / \mathrm{m}^{2} / \mathrm{s}\right)$; 
frequency $=1 ;$ damping $=2 ; \mathrm{Fm}=1.055$; $\mathrm{F}=0.950$. Light curve was initiated with ascending order of light intensities of $0,1,21$, 56, 111, 186, 281, 336, 396, 461, 531, 611 and $701 \mu \mathrm{mol} / \mathrm{m}^{2} / \mathrm{s}$ with blue light pilse in 20 second interval to get electron transport rate (ETR).

\section{Total chlorophyll}

Amount of total chlorophyll content of leaf tissue during flowering stage was determined according to the Arnon, 1949. $25 \mathrm{mg}$ of fresh leaf tissue was cut into pieces and placed in $10 \mathrm{ml}$ of $80 \%$ acetone. The samples were incubated at dark for 48 hours at $4^{\circ} \mathrm{C}$. After incubation, absorbance of the supernatant was measured at 645 and $663 \mathrm{~nm}$ using spectrophotometer (UV-2600, SHIMADZU, Europe). Total chlorophyll content was calculated by using the formula:

Total chlorophyll $\left(\mathrm{mg} \mathrm{g}^{-1} \mathrm{fw}\right)=20.2(\mathrm{OD}$ $645)+8.02(\mathrm{OD} 663) \times \mathrm{V} / \mathrm{W} \times 1000$

The unit is expressed as $\mathrm{mg} \mathrm{g}^{-1}$ fresh tissue weight.

Where, OD: Optical density

V: Final volume of solution $(10 \mathrm{ml})$

$\mathrm{W}$ : Weight of sample $(25 \mathrm{mg})$

\section{Leaf water potential (LWP)}

Leaf water potential was calculated using Barrs and Weatherley, 1962 method. Fully expanded $2^{\text {nd }}$ leaf from tip of the plant was collected at mid-day i.e. $12 \mathrm{pm}-2 \mathrm{pm}$ and LWP was measured using water potential system (psypro, WESCOR, USA).

\section{Relative Water Content (RWC)}

At mid day, healthy leaves were collected and cut into pieces. Immediately after collection, the fresh weights of cut leaves were determined. The cut leaves were immersed in water for 8 hours in petri-plates under room temperature. The turgid weight of the leaf samples were taken after blotting the leaves in blotting paper. Thereafter, dry weight of the leaves was taken after drying the leaves in hot air oven at $80^{\circ} \mathrm{C}$ till a constant weight was achieved (Bhushan et al., 2007). Relative water content was calculated using the formula:

RWC $(\%)=[($ Fresh weight- Oven dry weight $)$ / (turgid weight- Oven dry weight) ${ }^{*} 100$

\section{Statistical analysis}

All the data was taken from four replications. Pearson's correlation coefficient and p-value of the parameters were analyzed using Microsoft Excel. The statistical data analysis was done using Crop Stat 7.2 software (IRRI, 2009) and XLSTAT-2014 statistical software. ANOVA was carried out at 5\% level of significance for treatments and genotypes.

\section{Results and Discussion}

Chlorophyll a fluorescence parameters such as $\mathrm{Fm}, \mathrm{Fv} / \mathrm{Fm}, \mathrm{Fv} / \mathrm{F0}$ and ETR were measured to assess the photosynthetic efficiency of rice plants under WW and DS condition. Fm of all genotypes under DS condition was decreased significantly $(\mathrm{p}<0.05)$ over WW (Fig. 1 A). Under WW the value of Fm was in the range of 0.209-0.254 (Mean- 0.232) whereas, under DS the value of Fm was in the range of 0.1150.232 (Mean- 0.185). The genotypes IC 516008 (0.232) recorded higher value of Fm followed by IC $516313(0.230)$ and IC 516149 (0.228) whereas; IR 64 (0.116), Prasad (0.128) and Satabdi (0.133) recorded lower value of $\mathrm{Fm}$ under DS condition. Significant $(\mathrm{p}<0.05)$ reduction in $\mathrm{Fv} / \mathrm{Fm}$ value was also noticed in all the genotypes under DS condition (Fig. 2 B). Under WW, the $\mathrm{Fv} / \mathrm{Fm}$ value was in the range of 0.781- 0.806 
(Mean- 0.792), however, under DS, the value of $\mathrm{Fv} / \mathrm{Fm}$ was in the range of $0.523-0.775$ (Mean- 0.709). The genotypes Sahabhagidhan (0.775), Parijata (0.774) and IC 516130 (0.773) was able to maintained higher value of $\mathrm{Fv} / \mathrm{Fm}$ among all the genotypes while, lower value was observed in IR 64 (0.524) followed by Prasad (0.555) and Satabdi (0.618) under DS condition.

Similarly the value of Fv/F0 of all genotypes was reduced significantly compared with WW $(\mathrm{p}<0.05)$ (Fig. $1 \mathrm{C}$ ). Fv/F $\mathrm{F}_{0}$ value was ranged from 3.59- 4.16 (Mean- 3.84) under WW, on the other hand, the value was in the range of 1.24-3.47 (Mean- 2.69) under DS condition. The genotypes Parijata (3.47) sustained higher value followed by Sahabhagidhan (3.45) and IC 516149 (3.40) but, the lower value was recorded by IR 64 (1.24), Prasad (1.35) and Satabdi (1.62) under DS condition.

The ETR value of all studied genotypes was progressively increased towards higher light intensities under WW conditions (Fig. 2). The reduced value of ETR with increasing light intensities in susceptible genotypes clearly discriminating them from tolerant genotypes under DS. The value of ETR was maximum in the genotype IC 516130, Parijata and IC 516149 while, susceptible check IR 64 could not perform better in ETR and the value was zero at $336 \mu \mathrm{mol} \mathrm{m} \mathrm{m}^{-2} \mathrm{~s}^{-1}$ followed by Prasad (zero at $336 \mu \mathrm{mol} \mathrm{m} \mathrm{m}^{-2} \mathrm{~s}^{-1}$ ), Satabdi (zero at $396 \mu \mathrm{mol} \mathrm{m} \mathrm{m}^{-2} \mathrm{~s}^{-1}$ ) and Naveen (zero at 461 $\mu \mathrm{mol} \mathrm{m} \mathrm{s}^{-2}$ ).

Total chlorophyll content was significantly $(\mathrm{p}<0.05)$ reduced among all the genotypes under DS compared to WW (Fig. 3 A). The values of total chlorophyll content was 2.89 $\mathrm{mg} \mathrm{g}^{-1} \mathrm{fw}$ to $3.33 \mathrm{mg} \mathrm{g}^{-1} \mathrm{fw}$ (Mean- $3.11 \mathrm{mg} \mathrm{g}^{-}$ ${ }^{1} \mathrm{fw}$ ) under WW and $1.03 \mathrm{mg} \mathrm{g}^{-1}$ fw to $2.63 \mathrm{mg}$ $\mathrm{g}^{-1} \mathrm{fw}$ (Mean: $1.89 \mathrm{mg} \mathrm{g}^{-1} \mathrm{fw}$ ) under DS condition. The genotype IC $516130(2.63 \mathrm{mg}$ $\mathrm{g}^{-1} \mathrm{fw}$ ) able to uphold higher total chlorophyll content followed by Lalat $\left(2.29 \mathrm{mg} \mathrm{g}^{-1} \mathrm{fw}\right)$ and Sahabhagidhan (2.26 mg g $\left.\mathrm{g}^{-1} \mathrm{fw}\right)$ while, the value sharply reduced in susceptible check IR 64 (1.03 $\left.\mathrm{mg} \mathrm{g}^{-1} \mathrm{fw}\right)$ followed by Naveen (1.17 $\left.\mathrm{mg} \mathrm{g}^{-1} \mathrm{fw}\right)$ and Prasad (1.33 $\mathrm{mg} \mathrm{g}^{-1} \mathrm{fw}$ ) under DS.

The LWP value was significantly $(\mathrm{p}<0.05)$ reduced among all the genotypes under DS (Fig. $3 \mathrm{~B}$ ). The values was in the range from 1.41MPa to $-1.68 \mathrm{MPa}$ (Mean- $-1.50 \mathrm{MPa}$ ) under WW and $-2.59 \mathrm{MPa}$ to $-4.50 \mathrm{MPa}$ (Mean- -3.39MPa) under DS condition. Tolerant check Sahabhagidhan (-2.59 MPa) retained higher LWP trailed by Parijata (-2.61 $\mathrm{MPa})$ and IC $516149 \quad(-2.79 \mathrm{MPa})$. Simultaneously, Prasad (-4.50MPa), Satabdi (-4.32 MPa) and susceptible check IR 64 (4.17MPa) exhibited a quick reduction of LWP under DS.

Significant reduction $(\mathrm{p}<0.05)$ of RWC was noticed under DS condition among all the genotypes (Fig. $3 \mathrm{C}$ ). The values of RWC ranged $84.76 \%$ to $90.55 \%$ (Mean- $87.78 \%$ ) under WW and $25.86 \%$ to $70.25 \%$ (Mean: $55.54 \%$ ) under DS condition. The genotypes Sahabhagidhan $(70.25 \%)$ was recorded with the highest value followed by IC 516130 (70.21\%) and IC $516313(69.25 \%)$ whereas, Prasad $(25.86 \%)$, IR 64 (27.11\%) and Naveen (32.37\%) possessed lower RWC value under DS condition. The RWC value was sharply reduced in susceptible genotypes as compared with the tolerant genotypes.

\section{Correlation among different traits}

The correlation matrix among different traits under DS (Table 1) illustrated that, Fm had highly positive significant association with Fv/Fm $(p<0.01), \quad$ Fv/F0 $\quad(p<0.01), \quad$ total chlorophyll content $(\mathrm{p}<0.01)$, LWP $(\mathrm{p}<0.01)$ and RWC $(\mathrm{p}<0.01)$. Fv/Fm positively and significantly associated with Fv/F0 ( $<<0.01)$, total chlorophyll $(\mathrm{p}<0.01)$ LWP $(\mathrm{p}<0.01)$ 
and RWC ( $\mathrm{p}<0.01)$. Fv/F0 showed highly positive significant relationship with total chlorophyll $(\mathrm{p}<0.01)$, LWP $(\mathrm{p}<0.01)$ and RWC ( $<<$ 0.01). Total chlorophyll was positively and significantly associated with LWP ( $<<0.01)$ and RWC ( $<<0.01)$. LWP showed highly positive significant correlation with RWC ( $<<0.01)$ under DS condition.

Table.1 Correlation matrix among different chlorophyll fluorescence parameters, chlorophyll content, LWP and RWC of rice under drought stress condition

\begin{tabular}{|l|c|c|c|c|c|}
\hline Parameters & Fm & Fv/Fm & Fv/FO & Total chlorophyll & LWP \\
\hline Fv/Fm & $0.878^{*}$ & & & & \\
\hline Fv/FO & $0.926^{*}$ & $0.947^{*}$ & & & \\
\hline Total chlorophyll & $0.648^{*}$ & $0.619^{*}$ & $0.663^{*}$ & & \\
\hline LWP & $0.769^{*}$ & $0.667^{*}$ & $0.735^{*}$ & $0.653^{*}$ & \\
\hline RWC & $0.784^{*}$ & $0.746^{*}$ & $0.792^{*}$ & $0.704^{*}$ & $0.747^{*}$ \\
\hline
\end{tabular}

Fm- maximum fluorescence; Fv/Fm- maximum quantum yield of PSII photochemistry; Fv/F0- maximum primary yield of PSII photochemistry; LWP- leaf water potential; RWC- relative water content.

* Correlation is significant at the 0.01 level

Fig.1 The value of Fm, Fv/Fm and Fv/F0 under WW and DS condition respectively at flowering stage. Fm- maximum fluorescence; Fv/Fm- maximum quantum yield of PSII photochemistry; Fv/F0- maximum primary yield of PSII photochemistry; WW- well water; DS- drought stress, Sahabhagidhan and IR 64 are popular tolerant and susceptible controls respectively. Values are expressed as means $\pm \mathrm{SE}$ ( $\mathrm{n}=4$ biological replications)
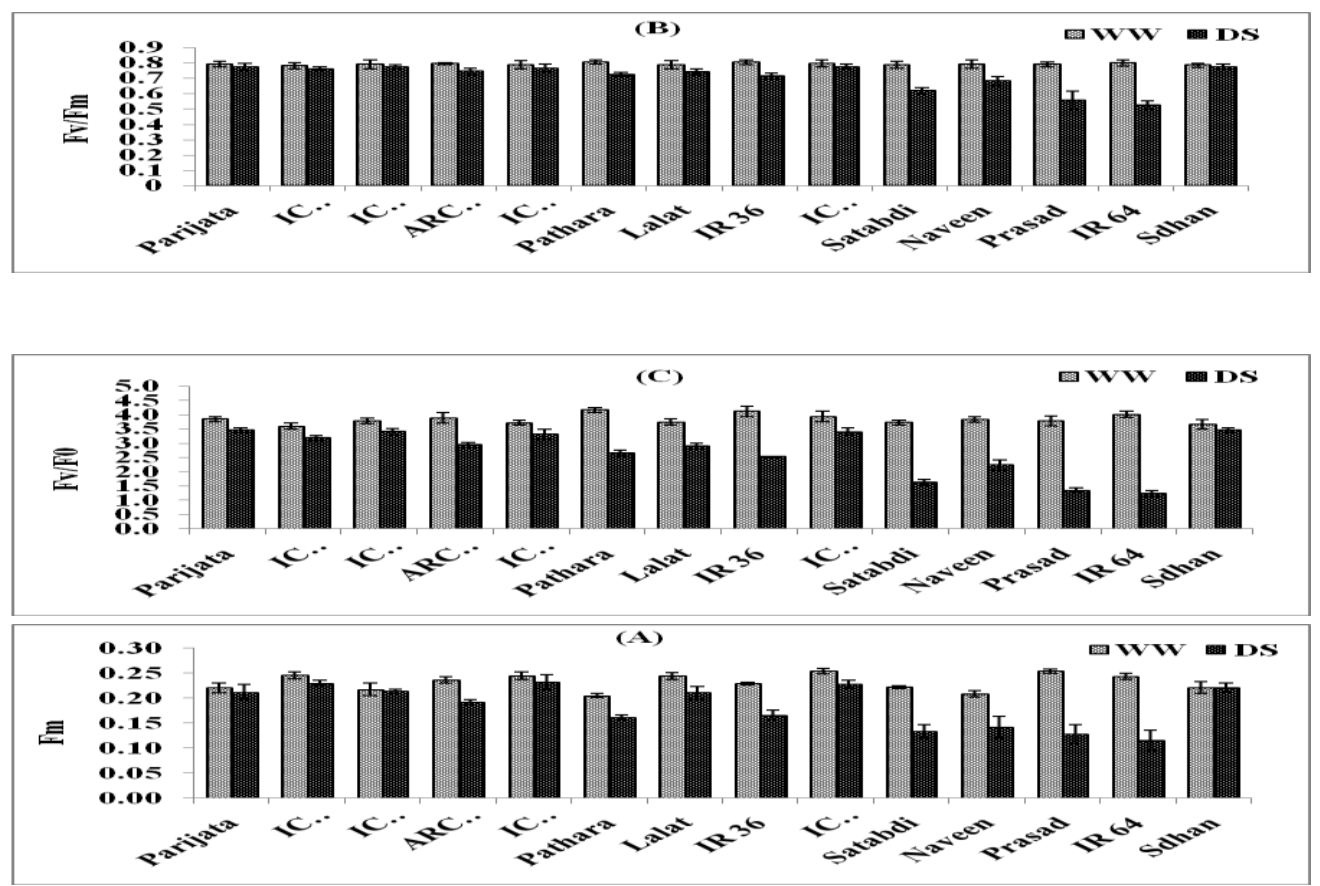
Fig.2 Changes in electron transport rate (ETR) with increasing light intensities at different PAR $\left(0-701 \mu \mathrm{mol} \mathrm{m} \mathrm{m}^{-2} \mathrm{~s}^{-1}\right)$ of fourteen rice genotypes under WW and DS condition at flowering stage.

WW- well water; DS- drought stress, Sahabhagidhan and IR 64 are popular tolerant and susceptible controls respectively. Values are expressed as means $\pm \mathrm{SE}$ ( $\mathrm{n}=4$ biological replications)
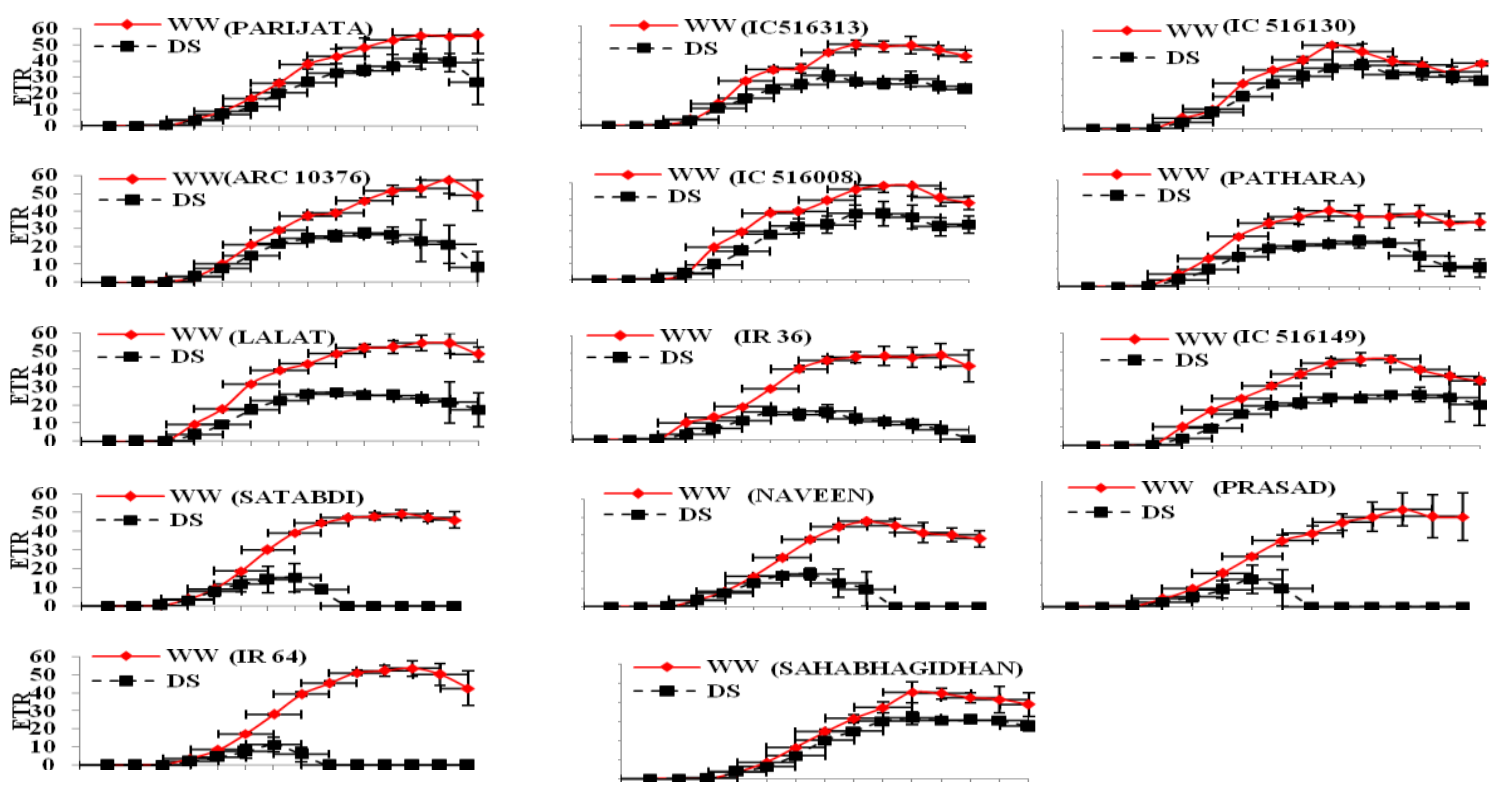

Fig.3 The value of total chlorophyll, LWP and RWC under WW and DS condition respectively at flowering stage. LWP- leaf water potential; RWC- relative water content; WW- well water;

DS- drought stress, Sahabhagidhan and IR 64 are popular tolerant and susceptible controls respectively. Values are expressed as means $\pm \mathrm{SE}$ ( $\mathrm{n}=4$ biological replications)
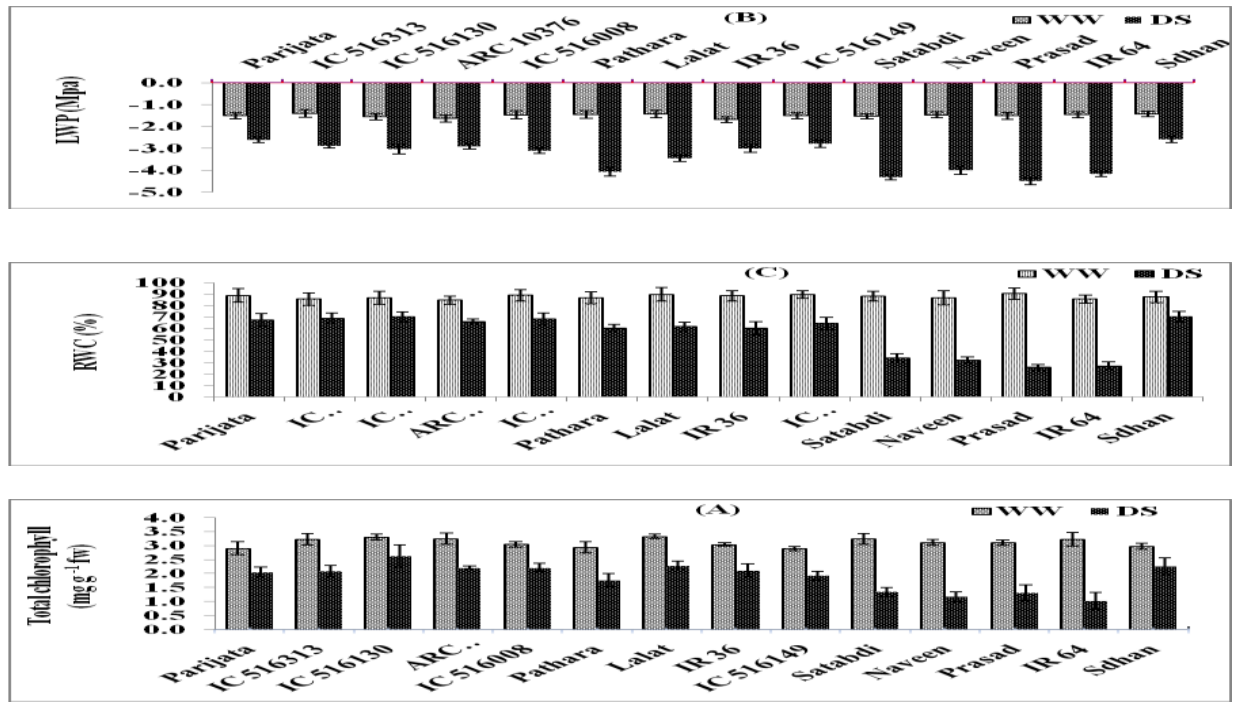
At physiological level tolerance to drought stress is governed by multiple traits. The photosynthetic efficiency of photosystem is severely damaged under drought (Wada et al., 2019). Chlorophyll fluorescence is most employed ecophysiological techniques that can provide useful information regarding photosynthetic process vis-à-vis quenching analysis of PSII reaction centre. The parameters of chlorophyll fluorescence could be used to evaluate the intensity of stress tolerance under drought, that are reliable and reproducible (Verulkar et al., 2010; Serraj et al., 2011). The technique of chlorophyll fluorescence can distinguish between tolerant and susceptible genotypes and characterizes the health status of photosystem II. $F_{m}$ is the maximum fluorescence yields that are responsible to measures the stability of photosynthetic apparatus (Percival et al., 2003) and is the indicator of PSII activity of photochemistry (Gashi et al., 2013). Our results illustrated that under drought Fm value was significantly reduced compared to WW and tolerant genotypes (Parijata, IC 516130, IC 516008 and IC 516149) able to maintain a higher value of Fm. The reduction in the value might be due to blocking in electron transfer to $\mathrm{Q}_{\mathrm{A}}$ (primary electron acceptor) in PSII, thus reduce in the oxygen-evolving complex proteins $(18 \mathrm{kDa}, 23 \mathrm{kDa}$ and 33 $\mathrm{kDa}$ ) and results in disruption of lightharvesting complex (Dalal and Tripathy, 2018).

Maximum quantum yield of PSII photochemistry (Fv/Fm) characterizes the healthiness of photosynthetic capacity (Panda et al., 2008; Sarkar and Ray, 2016). Under drought, the value of $\mathrm{Fv} / \mathrm{Fm}$ is decreased significantly compared to WW condition and provide a rapid way to evaluate the genotypes (Wang et al., 2018). Maintenance of higher value of $\mathrm{Fv} / \mathrm{Fm}$ under stress period is signified better health and could be considered as tolerant genotypes. The observed changes in $\mathrm{Fv} / \mathrm{Fm}$ values under stress are in agreement with the findings of Lichtenthaler et al., 2005 and Gashi et al., 2013. The reduction in Fv/Fm value might be due to photo inhibition, the poorer performance of PS II activity, the accumulation of free radicals which impaired Rubisco activity and promoted stomata closer, therefore the entry of $\mathrm{CO}_{2}$ to the photosynthetic apparatus is reduced. Concurrently, a greater restriction in photosynthesis and down regulation of energy transport from light harvest complex to the reaction centre of PSII core complex is imposed due drought (Zhou et al., 2007; Xu et al., 2020)

Similarly, another chlorophyll fluorescence parameter i.e. Fv/F0 evaluates the maximum primary yield of PSII photochemistry and indicators of photosynthetic capacity or photo-inhibition (LI et al., 2006). In the present study, Fv/F0 values were almost constant among the genotypes measured under WW and were found to reduce significantly under DS conditions. Tolerant genotypes (Parijata, IC 516130, IC 516008 and IC 516149) showed a little reduction in the value over susceptible genotypes (Prasad, Satabdi and Naveen). Our findings corroborate with the findings of (Borkowska, 2002; Puteh et al., 2013). Together the reduction in Fm, Fv/Fm and Fv/F0 might be due to the disruption of photosynthetic apparatus implies, injury to antennae structure and disturbance in PSII electron transport systems (Percival et al., 2003). Again, tolerant genotypes maintain the greater value of ETR under different light intensities. Higher ETR along with better $\mathrm{Fv} / \mathrm{Fm}$ is a good indicator of PSII photochemistry (Dalal and Tripathy, 2018).

The plants having lesser tissue hydration under drought stress can maintain their RWC and LWP which signify that RWC and LWP 
are good indicators for drought tolerance (Silva et al., 2007; Bunnag and Pongthai, 2013). RWC and LWP were declined as the drought stress progress towards severity. Under drought stress, the tolerant genotypes showed a higher value of RWC and LWP than the susceptible genotypes which is consistent with the previous findings (Kumar et al., 2014; Swapna and Shylaraj, 2017). Maintaining the higher value of RWC and LWP signifies better protoplast hydration that results in healthiness of tissue under drought stress (Dash et al., 2017; Yang et al., 2019). Jaleel et al., 2008 reported that drought stress can disrupt chlorophyll synthesis. The reduction in tissue greenness is mainly due to disruption of chloroplast membrane, degradation of chlorophyll and photosynthetic pigments (Yang et al., 2014), that accelerated leaf senescence (McCree and Fernandez, 1989; Raikhel, 2003). In our study, the tolerant genotypes maintained higher total chlorophyll content under drought stress and the value was significantly correlated with LWP, RWC, Fv/Fm and Fv/F0. The genotypes Parijata, IC 516130, IC 516008 and IC 516149 showed minimum reduction in these parameters compared to other genotypes under drought stress. The reduction was more pronounced in the genotypes Prasad, Satabdi and Naveen indicating these genotypes were more susceptible to drought stress at flowering stage. Moreover, the association of Fm, Fv/Fm, Fv/F0, total chlorophyll, LWP and RWC were highly efficient in evaluating the tolerance level under drought stress.

In conclusion besides the identification of tolerant genotypes under drought stress, attention has been inclined to the recognition of appropriate techniques with suitable traits that can precisely differentiate the tolerant and susceptible genotypes. Targeting the photosynthetic efficiency, the chlorophyll fluorescence technique was found to be very sensitive and provide significant phenotypic information regarding different sensitivity levels of genotypes under drought stress. In the present experiment, we found that different chlorophyll fluorescence parameters i.e., Fm, Fv/Fm and Fv/F0 provide accurate phenotypic information based on their tolerance level. Light curve data was very sensitive and could be widely used for precise phenotyping of a large population-based on their different levels of tolerance. Strong correlations between these parameters suggested that these parameters should be studied in the association while evaluating drought tolerance. However, the genotypes Parijata, IC 516130, IC 516008 and IC 516149 showed more tolerant to drought stress maintaining higher values for chlorophyll fluorescence parameters, chlorophyll content, LWP and RWC.

\section{Author contributions}

All the experimental analysis as well as drafting of the manuscript with statistical analysis was performed by SP, GKD, MB and SKS under the supervision of Dr. RP, Dr. PS and Dr. MJB. All the authors read and approved the final manuscript.

\section{Acknowledgements}

Authors are thankful to the NICRA (National Innovation on climate resilient Agriculture) project for providing financial support to conduct this experiment.

\section{Conflict of interest}

The authors declare that they have no conflict of interest.

\section{References}

Arnon, D. I. (1949). Copper Enzymes in Isolated Chloroplasts. Polyphenoloxidase in Beta Vulgaris. 
Plant Physiol. 24, 1-15.

Barrs, H., and Weatherley, P. (1962). A reexamination of the relative turgidity technique for estimating water deficits in leaves. Aust.J.Biol.Sci, 413-428.

Bhushan, D., Pandey, A., Choudhary, M. K., Datta, A., Chakraborty, S., and Chakraborty, N. (2007). Comparative proteomics analysis of differentially expressed proteins in chickpea extracellular matrix during dehydration stress. Mol. Cell. Proteomics 6, 18681884.

Borkowska, B. (2002). Growth and photosynthetic activity of micropropagated strawberry plants inoculated with endomycorrhizal fungi (AMF) and growing under drought stress. Acta Physiol. Plant. 24, 365-370.

Bunnag, S., and Pongthai, P. (2013). Selection of Rice (Oryza sativa L.) Cultivars Tolerant to Drought Stress at the Vegetative Stage under Field Conditions. Am. J. Plant Sci. 04, 17011708.

CRRI-ICAR (2011). Vision 2030.

Dalal, V. K., and Tripathy, B. C. (2018). Water-stress induced downsizing of light-harvesting antenna complex protects developing rice seedlings from photo-oxidative damage. Sci. Rep. 8, $10-16$.

Dash, G. K., Barik, M., Debata, A. K., Baig, M. J., and Swain, P. (2017). Identification of most important rice root morphological markers in response to contrasting moisture regimes under vegetative stage drought. Acta Physiol. Plant. 39: 8.

Datta, K., Baisakh, N., Ganguly, M., Krishnan, S., Shinozaki, K. Y., and Datta, S. K. (2012). Overexpression of Arabidopsis and Rice stress genes' inducible transcription factor confers drought and salinity tolerance to rice. Plant Biotechnol. J. 10, 579-586.
Eliazer Nelson, A. R. L., Ravichandran, K., and Antony, U. (2019). The impact of the Green Revolution on indigenous crops of India. J. Ethn. Foods 6, 1-10.

Gashi, B., Babani, F., and Kongjika, E. (2013). Chlorophyll fluorescence imaging of photosynthetic activity and pigment contents of the resurrection plants Ramonda serbica and Ramonda nathaliae during dehydration and rehydration. 19, 333-341.

Geda, C. K., Repalli, S. K., Dash, G. K., Swain, P., and Rao, G. J. N. (2019). Rice Research: Open Access Enhancement of Drought Tolerance in Rice through Introgression of Arabidopsis DREB1A through Transgenic Approach. Rice Res. 7, 411.

Guidi, L., Lo Piccolo, E., and Landi, M. (2019). Chlorophyll fluorescence, photoinhibition and abiotic stress: Does it make any difference the fact to be a C3 or C4 species? Front. Plant Sci. 10, $1-11$.

Jaleel, C. A., Manivannan, P., Lakshmanan, G. M. A., Gomathinayagam, M., and Panneerselvam, R. (2008). Alterations in morphological parameters and photosynthetic pigment responses of Catharanthus roseus under soil water deficits. Colloids Surfaces B Biointerfaces 61, 298-303.

Kumar, S., Dwivedi, S. K., Singh, S. S., Bhatt, B. P., Mehta, P., Elanchezhian, R., et al., (2014). Morpho-physiological traits associated with reproductive stage drought tolerance of rice (Oryza sativa L.) genotypes under rain-fed condition of eastern Indo-Gangetic Plain. Indian J. Plant Physiol. 19, 87-93.

LI, R. hua, GUO, P. guo, Michael, B., Stefania, G., and Salvatore, C. (2006). Evaluation of Chlorophyll Content and Fluorescence Parameters as Indicators of Drought Tolerance in Barley. Agric. 
Sci. China 5, 751-757.

Lichtenthaler, H. K., Langsdorf, G., Lenk, S., and Buschmann, C. (2005). Chlorophyll fluorescence imaging of photosynthetic activity with the flash-lamp fluorescence imaging system. Photosynthetica 43, 355-369.

McCree, K. J., and Fernandez, C. J. (1989). Simulation model for studying physiological water stress responses of whole plants. Crop Sci. 29, 353-360.

Panda, D., Sharma, S. G., and Sarkar, R. K. (2008). Fast chlorophyll fluorescence transients as selection tools for submergence tolerance in rice (Oryza sativa). Indian J. Agric. Sci. 78, 933939.

Percival, G. C., Fraser, G. A., and Oxenham, G. (2003). Foliar salt tolerance of Acer genotypes using chlorophyll flourescence. J. Arboric. 29, 61-65.

Puteh, A. B., Saragih, A. A., Ismail, M. R., Monjurul, M., and Mondal, A. (2013). Fluorescence Under Drought. 7, 12771283.

Raikhel, N. V. (2003). Plant Physiology's Best Paper award 2002.

Sarkar, R. K., and Ray, A. (2016). Submergence-tolerant rice withstands complete submergence even in saline water: Probing through chlorophyll a fluorescence induction O-J-I-P transients. Photosynthetica 54, 275287.

Selvaraj, M. G., Ishizaki, T., Valencia, M., Ogawa, S., Dedicova, B., Ogata, T., et al., (2017). Overexpression of an Arabidopsis thaliana galactinol synthase gene improves drought tolerance in transgenic rice and increased grain yield in the field. Plant Biotechnol. J. 15, 1465-1477.

Serraj, R., McNally, K. L., Slamet-Loedin, I., Kohli, A., Haefele, S. M., Atlin, G., et al., (2011). Drought resistance improvement in rice: An integrated genetic and resource management strategy. Plant Prod. Sci. 14, 1-14.

Silva, M. D. A., Jifon, J. L., Da Silva, J. A. G., and Sharma, V. (2007). Use of physiological parameters as fast tools to screen for drought tolerance in sugarcane. Brazilian J. Plant Physiol. 19, 193-201.

Sone, C., Ito, O., and Sakagami, J. I. (2012). Characterizing Submergence Survival Strategy in Rice Via Chlorophyll Fluorescence. J. Agron. Crop Sci. 198, 152-160.

Swain, P., Raman, A., Singh, S. P., and Kumar, A. (2017). Breeding drought tolerant rice for shallow rainfed ecosystem of eastern India. F. Crop. Res. 209, 168-178.

Swapna, S., and Shylaraj, K. S. (2017). Screening for Osmotic Stress Responses in Rice Varieties under Drought Condition. Rice Sci. 24, 253-263.

Verulkar, S. B., Mandal, N. P., Dwivedi, J. L., Singh, B. N., Sinha, P. K., Mahato, R. N., et al., (2010). Breeding resilient and productive genotypes adapted to drought-prone rainfed ecosystem of India. F. Crop. Res. 117, 197-208.

Vikram, P., Swamy, B. P. M., Dixit, S., Ahmed, H. U., Teresa, M., and Cruz, S. (2011). Reproductive-Stage Drought Stress With a Consistent Effect in Multiple Elite Genetic Backgrounds. BMC Genet. 12, 1-15.

Wada, S., Takagi, D., Miyake, C., and Makino, A. (2019). Responses of the Photosynthetic Electron Transport Reactions Stimulate the Oxidation of the Reaction Center Chlorophyll of Photosystem I, P700, under Drought and High Temperatures in Rice. 20, 116.

Wang, Z., Li, G., Sun, H., Ma, L., Guo, Y., Zhao, Z., et al., (2018). Effects of drought stress on photosynthesis and photosynthetic electron transport chain 
in young apple tree leaves. Biol. Open $7,1-9$.

Xu, Q., Ma, X., Lv, T., Bai, M., Wang, Z., and Niu, J. (2020). Effects of water stress on fluorescence parameters and photosynthetic characteristics of drip irrigation in rice. Water (Switzerland) 12.

Yang, P. M., Huang, Q. C., Qin, G. Y., Zhao, S. P., and Zhou, J. G. (2014). Different drought-stress responses in photosynthesis and reactive oxygen metabolism between autotetraploid and diploid rice. Photosynthetica 52, 193202.

Yang, X., Wang, B., Chen, L., Li, P., and Cao, C. (2019). The different influences of drought stress at the flowering stage on rice physiological traits, grain yield, and quality. Sci. Rep. 9, 1-12.

Zhou, Y., Lam, H. M., and Zhang, J. (2007). Inhibition of photosynthesis and energy dissipation induced by water and high light stresses in rice. J. Exp. Bot. 58, 1207-1217.

\section{How to cite this article:}

Selukash Parida, Goutam Kumar Dash, Madhusmita Barik, Soumya Kumar Sahoo, Rajendra Kumar Panda, Mirza Jaynul Baig, Padmini Swain. 2021. Photosystem II Photochemistry and Chlorophyll Intensity in Rice (Oryza sativa L.) under Drought at Flowering Stage. Int.J.Curr.Microbiol.App.Sci. 10(02): 746-756. doi: https://doi.org/10.20546/ijcmas.2021.1002.089 